Alessandra Craig Cerello ${ }^{1}$

Ingrid Faria Gianordoli-Nascimento ${ }^{2}$

Alline Hellen Moreira ${ }^{2}$

Virgínia Silva Rocha ${ }^{2}$

Luciana de Moura Ribeiro ${ }^{2}$

Nilton Alves de Rezende ${ }^{1}$

${ }^{1}$ Faculdade de Medicina, Universidade Federal de Minas Gerais. Av. Prof. Alfredo Balena 190, Santa Efigênia. 30.130-100; Belo Horizonte MG. alecerello@ufmg.br ${ }^{2}$ Departamento de Psicologia, Universidade Federal de Minas Gerais.

\section{Representações sociais de pacientes e familiares sobre neurofibromatose tipo 1}

\author{
Social representations of patients and relatives \\ regarding Type 1 Neurofibromatosis
}

Abstract Type 1 Neurofibromatosis (NF1) is a disease with diverse manifestations. Few studies have addressed the psychological aspects associated with it from the perspective of those who have NF1 or their relatives. In this study 46 subjects were interviewed, 28 people with NF1 (Group P) and 18 relatives (Group F) seeking to identify the understanding of the day-to-day reality experienced by these two groups and possible distinctions between them, based on the social representations of each group. Data analysis was conducted using Classic Content Analysis. The respondents' answers were organized into categories and subcategories based on their meanings. The results revealed that the quantitative distribution of the categories had similar frequencies for both groups. However, important qualitative differences were observed in terms of the meanings of the answers. Difficulty in obtaining information about NF1 along with few references about social support networks by people with the disease or their family members contributed to the identification of a veil of social invisibility around NF1. These aspects highlight the need for greater investment in research and intervention related to NF1 in order to expand the social coping conditions for those afflicted with the disease.

Key words Social psychology, Neurofibromatosis, Social representations, Health
Resumo A Neurofibromatose do tipo 1 (NF1) é uma doença com manifestações variadas. Poucos estudos abordaram os aspectos psicológicos associados a ela sob a ótica daqueles que têm NF1 ou de seus familiares. Neste estudo foram entrevistados 46 sujeitos, 28 pessoas com NF1 e 18 familiares, buscando-se identificar a compreensão da realidade cotidiana vivenciada por esses dois grupos e as possíveis diferenças entre eles, a partir do aporte teórico das representações sociais. O tratamento dos dados foi realizado com base na análise de conteúdo clássica, sendo organizadas em categorias e subcategorias a partir de seu sentido. Os resultados mostraram que a distribuição quantitativa por categorias teve frequências semelhantes para os grupos, mas diferenças qualitativas importantes foram observadas no que se refere ao sentido das respostas. Dificuldade na obtenção de informações sobre NF1 somado a poucas menções a redes sociais de apoio às pessoas com a doença ou seus familiares contribuiram para a identificação de um cenário de invisibilidade social em torno da NF1. Tais aspectos evidenciam a necessidade de maiores investimentos em estudos e intervenções relacionados à NF1, a fim de ampliar as condições de enfrentamento social da doença por parte daqueles que a vivenciam.

Palavras-chave Psicologia social, Neurofibromatose, Representações sociais, Saúde 


\section{Introdução}

Neurofibromatose (NF) é o nome para um grupo de três doenças genéticas: a tipo 1 (NF1), a tipo 2 (NF2) e a schwanomatose ${ }^{1}$. Dentre elas, a NF1 é mais frequente, ocorrendo em cerca de uma a cada 2.500 crianças nascidas vivas ${ }^{2}$. A NF2 e a schwanomatose, menos prevalentes, ocorrem em cerca de 1:40.000 3 . Apesar de sua prevalência, a NF1 é uma doença menos conhecida quando comparada a outras menos frequentes, como a Diabetes Mellitus tipo 1 (1:10000) ${ }^{4}$.

A NF1 decorre de uma anomalia de um gene do cromossomo 17, que resulta, entre outras situações, na alteração da síntese de uma proteína que participa na regulação o crescimento celular ${ }^{4}$. Em aproximadamente 50\% dos casos, o indivíduo herda esse gene com a mutação de um dos pais. Os demais casos são causados por novas mutações ${ }^{2,5}$. A falta dessa proteína torna os indivíduos susceptíveis ao desenvolvimento de tumores benignos ao longo do tecido nervoso central e periférico, assim como a possíveis alterações em outros tecidos, como o muscular e o ósseo ${ }^{6-8}$.

As manifestações clínicas ocorrem com gravidades diferentes para cada indivíduo, desde as mais discretas e benignas até as mais graves. Há situações com comprometimento multissistêmico, envolvendo diversos aspectos do funcionamento físico e cognitivos, capazes de interferir na vida cotidiana, como no aprendizado e no desenvolvimento ${ }^{8}$.

As publicações dedicadas aos aspectos subjetivos da NF1 ocorreram a partir da década de 80 , porém foram realizadas por poucos pesquisadores, e quase todos desenvolvidos no contexto norte-americano ${ }^{9-13}$

Dentre elas, os impactos das alterações na aparência física são possivelmente o aspecto mais citado. As preocupações, os medos, as incertezas e a ansiedade vividas em função das deformidades estéticas resultantes da NF1 são observadas tanto em algumas situações nas quais o paciente apresenta manifestações clínicas mínimas da doença, mas grande insatisfação com a aparência, quanto naquelas em que tais preocupações e sentimentos podem se configurar em uma queixa avaliada como mais relevantes pela pessoa, do que outras que envolvem alta gravidade clínica ${ }^{9,12}$. Nesse sentido, os autores apontam que as percepções de profissionais e pacientes sobre a gravidade da doença e sobre as queixas que merecem atenção e intervenção não são as mesmas ${ }^{11,12}$.

Outro foco de estudos pelos autores é a vida social das pessoas com NF1. Ablon ${ }^{12}$ destaca que o estigma social e a rejeição, apesar de serem aspectos de difícil avaliação e mensuração por meios objetivos, aparentam estar entre as queixas mais frequentes, inclusive quando comparadas com a dos sintomas físicos.

Recentemente há uma concentração do foco de atenção em avaliações de inteligência e processamento cognitivo das pessoas com NF1. As questões investigadas procuram avaliar a natureza das dificuldades de aprendizagem observadas nessas pessoas, visando a responder se seriam um déficit global de inteligência ou circunscritos a competências específicas, e ainda, se seriam resultado de alterações primárias no funcionamento cerebral ou decorrentes de outros fatores ${ }^{14}$.

As vivências de familiares são abordadas em estudos nos quais destaca-se a necessidade de atenção para suas reações, uma vez que os familiares também demonstraram impactos psicológicos, principalmente em períodos iniciais da doença e do diagnóstico, tais como incerteza e preocupação com a gravidade dos sintomas ${ }^{1,10,15}$. Para isso, sugerem intervenções que facilitem o acesso à rede de suporte social e a estratégias que ampliem a capacidade de lidar melhor com as dificuldades vivenciadas.

A formulação da pergunta que guiou esta investigação surgiu a partir da experiência com as atividades de pesquisa, extensão e ensino realizado pela equipe de psicologia no Centro de Referência em Neurofibromatose de Minas Gerais (CRNF-MG), através da parceria institucional entre o Departamento de Psicologia e o Hospital das Clínicas da Universidade Federal de Minas Gerais.

O objetivo principal do estudo foi apreender as Representações Sociais sobre a NF1 para pessoas com diagnóstico firmado e seus familiares, assim como as possíveis distinções entre esses grupos, compreendendo que a identificação dessas diferenças pode refletir práticas específicas e, nesse sentindo, a necessidade de que sejam pensadas e propostas intervenções focadas em cada uma das situações.

\section{Aporte teórico}

A Teoria das Representações Sociais (TRS) parte de uma perspectiva que busca a compreensão do ser humano considerando-o a partir de um duplo papel: como sujeito construído a partir de suas determinações evolutivas, históricas, culturais e sociais e, ao mesmo tempo, construtor de sua realidade social. Nessa construção psicossocial, os saberes simbólicos são produzidos 
na vida cotidiana pelas práticas e conversações socialmente elaborados e partilhados ${ }^{16,17}$. Assim, a TRS propõe identificar as teorizações do senso comum e como estas coexistem com as científicas, visto que não são nem paralelas nem equilibradas, pois o cotidiano e o movimento histórico fazem com que ocorra uma apropriação seletiva e a transformação do conhecimento científico pelo senso comum em função dos interesses, crenças e valores do grupo em questão. Nessa perspectiva, o conhecimento leigo deixa de ser considerado como um saber inferior, quando comparado ao saber médico, e sim percebido como autônomo, com uma lógica e uma coerência próprias, cuja análise pode ser fundamental para a eficácia do tratamento e principalmente para o sucesso dos projetos sociais de saúde ${ }^{18}$.

Sendo assim, a TRS aborda um objeto que é partilhado socialmente por um grupo e que concede sentido às experiências coletiva e individual, além de se articular às práticas e contribuir para a manutenção da identidade social desse mesmo grupo. Dessa forma, a TRS envolve, como critério, a existência de um objeto - aquilo que está sendo estudado - e um sujeito, aquele que representa o que está sendo estudado ${ }^{19}$. No presente estudo esse sujeito é composto por dois grupos: pessoas com NF1 e seus familiares. Já o objeto é a representação social do termo "Neurofibromatose".

\section{Método}

\section{Participantes}

Os participantes da pesquisa foram adultos e idosos que estiveram presentes no CRNF-MG, durante o período da pesquisa, para consulta em qualquer uma das especialidades oferecidas (médica, psicológica ou fonoaudiológica). Optou-se por não incluir crianças e adolescentes neste momento da pesquisa, uma vez que eles poderiam compor um grupo com representações e práticas sociais próprios, o que tornaria a análise dos dados ainda mais complexa em função da multiplicidade de grupos avaliados.

A coleta de dados foi realizada com dois grupos distintos: 28 pessoas com NF1 (Grupo P) e 18 familiares de pessoas com NF1 (Grupo F), totalizando uma amostra de 46 entrevistados. A escolha pela inclusão de dois grupos foi baseada na observação clínica durante os atendimentos de que as demandas apresentadas por eles era distinta, o que gerou a suposição de que estariam associadas a construções diferentes, pautadas em representações e práticas sociais próprias para cada grupo.

\section{Instrumento de coleta de dados}

O roteiro de entrevistas utilizado na coleta foi semiestruturado e estruturado em duas partes: a primeira, relativa aos dados pessoais e à história da doença do entrevistado ou familiar. Na segunda parte foi utilizada a Técnica para Associação Livre de Palavras, que consiste na utilização de um termo indutor para evocação espontânea de expressões, ideias e palavras pelo entrevistado, buscando-se acesso a elementos semânticos que, para os entrevistados, se articulam com o objeto estudado ${ }^{14}$. Para isso, foi utilizado o termo indutor "Neurofibromatose".

\section{Procedimento}

A coleta ocorreu entre novembro de 2007 e novembro de 2008. Foram convidados para a pesquisa os adultos e idosos que estavam na sala de espera aguardando por atendimentos da equipe multidisciplinar do CRNF-MG . Aqueles que manifestaram interesse e concordaram em participar, receberam mais informações sobre a pesquisa, seguidos da leitura e assinatura do termo de consentimento livre e esclarecido para participação em pesquisas, aprovado juntamente com o protocolo de pesquisa pelo Comitê de Ética em Pesquisas da UFMG.

\section{Tratamento dos dados}

Os dados foram tratados a partir da análise de conteúdo categorial temática, considerada análise de conteúdo clássica ${ }^{20,21}$, composta por etapas: 1) constituição do corpus com as respostas das pessoas com NF1 (Grupo P) e de familiares (Grupo F); 2) leitura inicial flutuante das entrevistas para identificação de temas semelhantes nos discursos dos entrevistados e posterior construção de categorias e subcategorias; 3 ) a categorização propriamente dita, quando as respostas foram alocadas nas categorias e subcategorias construídas, 4) a quantificação percentual das respostas categorizadas; e 5) a análise qualitativa dos significados contidos em cada categoria e subcategoria, assim como as possíveis articulações de sentidos entre elas. 


\section{Resultados}

A amostra foi composta por 46 participantes, sendo 28 do Grupo P e 18 do Grupo F.

Grupo P: 28 pessoas, 19 mulheres $(67,85 \%)$ e 9 homens $(32,14 \%)$, com idades variando entre 18 e 65 anos (média 36,29 e desvio padrão 11,67), com maior concentração na faixa entre 25 a 34 anos (32,14\%). A maior parte dos sujeitos (50\%) frequentou pelo menos 11 anos de escolarização formal em instituições de ensino a partir da primeira série. Aqueles que cursaram de um a quatro anos representam 10,71\% dos entrevistados e 3,57\% nunca foram à escola ou o fizeram por menos de um ano.

Grupo F: 18 pessoas, 17 mulheres (94,44\%) e 1 homem (5,55\%), com idades variando entre $25 \mathrm{e}$ 65 anos (média 40,67; desvio padrão 8,48) e maior concentração na faixa entre 35 a 44 anos $(61,11 \%)$. As maiores frequências de escolaridade encontradas foram para os que estudaram entre 8 e 11 anos (38.89\%), seguidas por aqueles com escolaridade abaixo de quatro anos de educação formal $(22.22 \%)$. As faixas de escolaridade que correspondem tanto ao intervalo entre 4 e 8 anos, como àqueles com nível superior completo representaram $16,67 \%$ cada. O Grupo F foi composto majoritariamente por mães de pessoas com NF1 (13 sujeitos). Além disso, verificou-se a presença de uma irmã, duas tias, uma madrasta e um pai.

O número total de respostas obtidas nas entrevistas foi de 70 no Grupo P e 60 no Grupo F, em média 2,50 e 3,33 respostas por sujeito, respectivamente. Constituíram categorias apenas respostas com a mesma rede de significado apresentadas por mais de um participante. Além disso, para um mesmo entrevistado, as respostas compreendidas como pertencentes à mesma categoria foram contadas apenas uma vez, sendo entendidas como descrições da mesma situação. Optou-se por não formar categorias com respostas apresentadas por um único indivíduo, uma vez que se arriscaria considerar como coletivas as experiências específicas de um indivíduo. As respostas que não foram incluídas em alguma das categorias ou subcategorias construídas foram agrupadas em "Outras" (7,14\% no Grupo P e $1,66 \%$ no Grupo).

As categorias identificadas foram Enfrentamento da doença, Consequências negativas da doença, Sentimentos negativos, Desconhecimento/ ausência de explicações sobre a doença, Descrições sobre a doença, Atribuições de causas, Pensamento mágico-religioso e Outras e a distribuição percentual entre elas encontra-se no Gráfico 1.
As categorias serão caracterizadas e exemplificadas a seguir. Para aquelas com maior número de respostas, serão apresentadas as principais subcategorias construídas e apontadas diferenças qualitativas entre os dois grupos pesquisados.

Enfrentamento da doença: (Grupo P = 28,57\%; Grupo $F=26,67 \%$ ): diversas formas de lidar com a doença, relacionadas aos impactos na percepção de mundo, assim como às modificações nos hábitos, incluindo as ações avaliadas pelo sujeito como necessárias para melhorar sua com-vivência com a NF1.

Nesta categoria foram identificadas quatro subcategorias: Normal/Natural; Focado nas emoções/Processos Psicológicos; Focado no problemal Ação no corpo; Não tem o que fazer. As frequências estão ilustradas no Gráfico 2.

Para o Grupo P, duas subcategorias se destacaram com o mesmo percentual de respostas (35,00\%): Normal/Natural e Focado nas Emoções/ Processos Psicológicos. Entre as primeiras, as respostas revelam uma avaliação pelos sujeitos de que a convivência com a doença ou seus sintomas é encarada sem grandes dificuldades ou como uma situação habitual, por exemplo: Pra mim é normal, não sinto nada, não me incomoda; Convivo bem com ela; Já estou acostumado. As respostas em Focado nas Emoções/Processos Psicológicos foram caracterizadas por aquelas nas quais o enfrentamento da NF1 é uma busca pela adaptação, um processo que ocorre ao longo desta convivência com a doença: Trabalho, ando, tento ser superior a ela. Vivo como se não tivesse, não deixo ela atrapalhar; Saber lidar com ela, [...] tentar viver da melhor maneira.

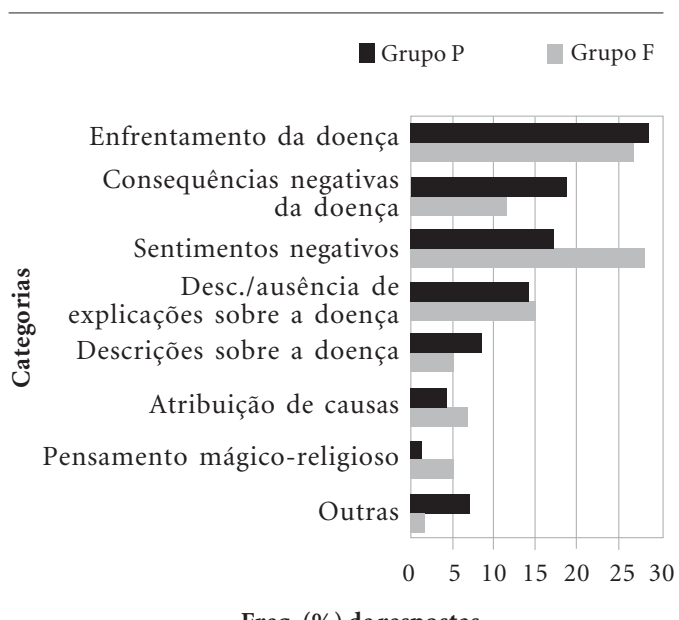

Freq. (\%) de respostas

Gráfico 1. Distribuição das respostas dos grupos P e $\mathrm{F}$ em categorias. 
As respostas classificadas como Voltadas ao Problema/Ação no Corpo (20,00\%), estiveram relacionadas à insatisfação com a existência dos neurofibromas, e a ações voltadas para tais sintomas: Retirada de fibromas; Tirar todos os fibromas, fazer uma plástica. Enquanto as respostas com o sentido oposto, Não tem o que fazer $(10,00 \%)$, demonstram a falta de ações voltadas à NF1 ao se perceberem diante da impossibilidade de cura ou pela incontrolabilidade sobre sua evolução: Situação que não pode fazer nada; Vai nascer mesmo [os neurofibromas].

No Grupo F, as respostas concentraram-se em maior número em Focado nas Emoções/Processos Psicológicos (50,00\%), e qualitativamente se caracterizam por respostas voltadas para ações em prol da aceitação da situação, por meio de modificações de pensamentos e comportamentos pessoais diante da NF1: É com a convivência, tem que aceitar; Eu me preparo para o que pode vir a acontecer. Demonstraram diferença de sentido em relação às respostas dessa mesma subcategoria para o Grupo P, pois as estratégias deste estão focadas no tempo presente, enquanto os familiares estão preocupados com o futuro, acerca de como a doença pode evoluir.

O grupo F também apresentou respostas nas subcategorias Voltadas ao Problema/Ações no Corpo $(25,00 \%)$ e Não tem o que fazer $(25,00 \%)$. Na primeira, os entrevistados mencionaram ações ao longo do tempo voltadas à procura por recursos de saúde disponíveis ou idealizados por eles como solução para a situação: Buscar um tratamento; Cuidar para amenizar a situação, tomar medicação. Ao contrário do Grupo P, não há

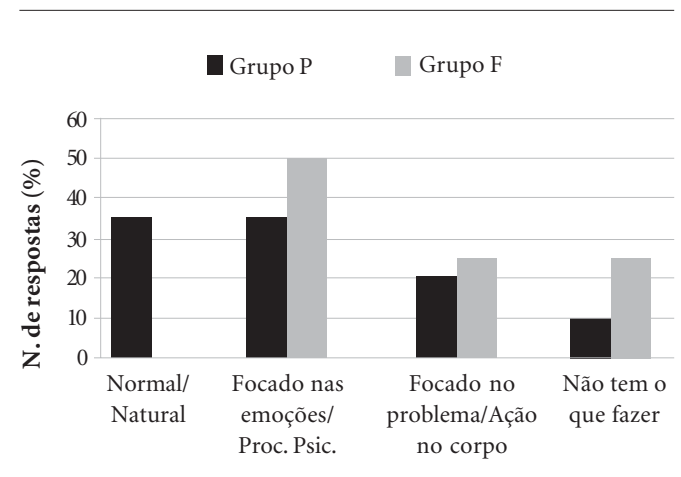

Subcategorias

Gráfico 2. Distribuição das respostas de "Enfrentamento da doença" em subcategorias para os grupos P e F. um foco nas ações especificamente voltadas aos neurofibromas, mas a uma ação mais ampla de cuidados, pelas buscas a consultas e atendimentos com profissionais de diversas áreas da saúde. Para a subcategoria Não tem o que fazer, o sentido das respostas para o Grupo F se aproxima ao do Grupo P e se relaciona com a ênfase na impossibilidade da cura e com a expectativa de como a doença irá se desenvolver. Não foram citadas pelo Grupo F respostas com o sentido de Normal/Natural. Esse dado, somado com o maior foco em estratégias de enfrentamento voltadas ao futuro por esse grupo em Focado nas Emoções/Processos Psicológicos, indicam uma preocupação mais evidente com relação à gravidade e à evolução da NF1 para os familiares.

Consequências negativas da doença: (Grupo P $=18,57 \%$; Grupo F = 11,67\%): qualquer tipo de impacto ou limitação, temporária ou permanente, em qualquer setor da vida, como consequência direta ou indireta da vivência com NF1, como: desempenho de atividades, relacionamentos familiares e socioafetivos, desempenho escolar, funcionamento do corpo e estética.

Esta categoria foi subdivida em três subcategorias: Limitações/Constrangimentos Sociais, Ausência de Cura e Gravidade da Doença, como pode ser observado no Gráfico 3.

Para o Grupo P, a subcategoria Limitações/ Constrangimentos Sociais foi a de maior frequência $(69,23 \%)$ e os sentidos das respostas foram relacionados à vivência de preconceito ou estigmatização em função da NF1, ou de relatos de redução da autonomia/independência, em respos-

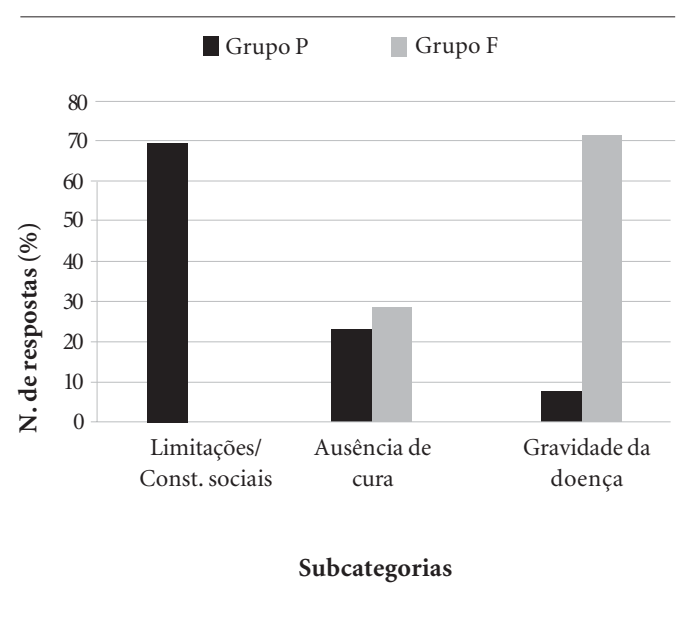

Gráfico 3. Distribuição das respostas de "Consequências negativas da doença" em subcategorias para os grupos $\mathrm{P}$ e F. 
tas como: Pessoa que tem vive sob os cuidados dos pais. Às vezes tem dificuldades em algumas matérias da escola; As pessoas ficam perguntando o que é; Todo mundo olhar para ela [neurofibromatose].

A Ausência de Cura (23,08\%) foi destacada por aqueles que têm a NF1: Doença que ainda não tem cura; Não tem cura. Em menor frequência, foram citadas pelo Grupo P respostas com o sentido de Gravidade da Doença (7,69\%), como no exemplo "Deformação".

Contrariamente ao Grupo P, a Gravidade da Doença foi a subcategoria que teve a maior frequência para o Grupo F (71,43\%), apresentando respostas do tipo: Que ela procura mais os ossos. Ela prejudica o corpo todo, principalmente os ossos, dá tumores; Está sendo uma das piores doenças que eu conheço. É uma doença que castiga muito a pessoa, pode deixar a pessoa deformada. Já as respostas com sentido de Limitações/Constrangimentos Sociais não foram citadas pelo Grupo F.

Assim, na categoria Consequências Negativas da Doença, apenas a Ausência de Cura (28,57\%, para o Grupo F) foi um aspecto com participação semelhante nos dois grupos.

Sentimentos negativos: (Grupo P $=17,14 \%$; Grupo $F=28,33 \%$ ): diversos tipos de sentimentos socialmente considerados negativos, como medo, tristeza, preocupação e vergonha.

Nessa categoria, houve grande heterogeneidade nas respostas, o que pode ser constatado pela proporção das respostas na subcategoria Outras (Grupo P = 25,00\%; Grupo $\mathrm{F}=29,41 \%$ ) formada por palavras mencionadas no máximo por dois sujeitos e que não puderam ser agrupadas, como pode ser observado no Gráfico 4.

O Medo é um sentimento que se destaca entre as respostas do Grupo P (41,67\%), enquanto no

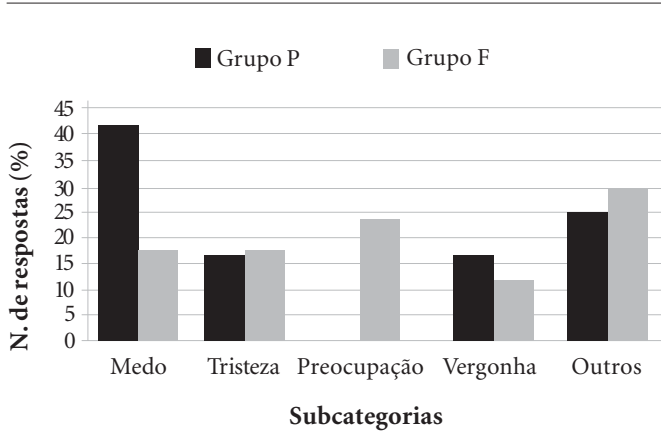

Gráfico 4. Distribuição das respostas de "sentimentos negativos" em subcategorias para os grupos P e F
Grupo F a distribuição é mais homogênea entre os diversos tipos de sentimentos. A Preocupação, que obteve a maior frequência para o Grupo $\mathrm{F}(23,53 \%)$, não foi mencionada pelos entrevistados do Grupo P. Tais diferenças entre os Grupos indicam que, também nesta categoria, o Grupo P demonstra um foco no momento presente, através dos receios atuais, enquanto o Grupo F no futuro, por meio de "Preocupação constante", referidas mais frequentemente quanto à evolução dos sintomas. Além disso, foram importantes as respostas Tristeza (Grupo P: 16,67\%, Grupo F: 17,65\%) e Vergonha (Grupo P: 13,33\%, Grupo F: 11,76\%.).

Desconhecimento/ausência de explicações sobre a doença: (Grupo P = 14,29\%; Grupo $\mathrm{F}=$ $15,00 \%)$ : ideias de desconhecimento, dúvidas ou desejo de maiores informações e divulgação com relação à doença, ao tratamento e à prevenção.

Os dois Grupos indicaram maior concentração de respostas entre aquelas que têm o sentido de Desconhecimento Pessoal (Grupo P =70,00\%; Grupo $\mathrm{F}=88,89 \%)$. Eu sempre tenho uma pergunta a fazer sobre ela [neurofibromatose], sempre existem dúvidas sobre a neurofibromatose.

O Desconhecimento Técnico-Científico (Grupo $\mathrm{P}=20,00 \%$, Grupo $\mathrm{F}=11,11 \%$ ) também foi apontado: Está em estudo ainda, tem tratamento e remédio, mas está sobre estudo. Doença que está meio complicada ainda. Doença que precisa realmente de aprofundar [...].

As respostas agrupadas em Outras, (10\% Grupo P) foram aquelas em que não foi possível determinar se o desconhecimento era pessoal ou técnico-científico, ou foram descritas por termos pouco definidos.

As categorias Descrições sobre a doença, Atribuições de causas e Pensamento mágico-religioso tiveram menor número de respostas e não foram divididas em subcategorias.

Descrições sobre a doença (Grupo $\mathrm{P}=8,5 \% \mathrm{e}$ Grupo $F=5,0 \%$ ): descrições de sinais e sintomas percebidos pelos entrevistados e associados à NF1. São exemplos: Caroços que eu tenho; Nódulos, manchas café-com-leite.

Atribuições de causas (Grupo P = 4,29\%; Grupo $\mathrm{F}=6,67 \%$ ): respostas relacionadas ao que os próprios participantes consideravam como causas da NF1, independente de ser corroborada pelo conhecimento científico. Nos sentidos encontrados houve uma ênfase nos aspectos familiares, genético e hereditário da doença: Pode ser alguma coisa de sangue; Doença pré-existente, nasceu com ela; Fico pensando se é genética, se é de família.

Pensamento mágico-religioso (Grupo $\mathrm{P}=$ 1,43\%; Grupo $\mathrm{F}=5,00 \%)$ : quando o entrevista- 
Cerca de um terço dos participantes do Grupo P foram homens e dois terços mulheres. Essa proporção com o dobro de mulheres é a mesma da população dos pacientes adultos atendidos no CRNF-MG, obtidos no banco de dados dos pacientes cadastrados até 2008. A predominância da presença das mulheres em atendimentos é uma questão discutida em estudos de gênero no âmbito da saúde ${ }^{22,23}$. Em contrapartida, a procura dos cuidados em saúde por homens ocorre quando este considera a situação como emergencial, por exemplo, em ocasiões nas quais há dor forte e persistente ou o risco à vida ${ }^{24,25}$.

O Grupo F foi composto quase exclusivamente por mulheres, mães de pessoas com NF1, com idades majoritariamente na faixa entre 35 e 44 anos, e escolaridade mais homogeneamente distribuída entre as diversas faixas, ainda que com maiores frequências entre as que estudaram entre 8 e 11 anos. No que diz respeito ao papel dos cuidadores, Trindade ${ }^{25}$ afirma que a predominância de mulheres e mesmo de mães demonstra aspectos das diferentes formas de socialização masculina e feminina, ainda presentes nos dias atuais. Os meninos seriam educados "para a vida", e as meninas "para o lar". Isso seria refletido na idade adulta nos papéis assumidos por cada um, de forma que os homens assumiriam apenas de maneira periférica os assuntos relacionados à saúde da família, enquanto o exercício da maternagem e o papel de cuidadora estariam entre as características femininas esperadas como resultado do processo de socialização feminino desde a infância ${ }^{24}$.

De uma forma geral, os resultados encontrados no trabalho atual estão de acordo com os descritos na literatura, no que diz respeito aos aspectos socioemocionais da NF1, como nas experiências de estigmatização e preconceito ${ }^{1,12}$.

A dificuldade para se obter informações corretas sobre a neurofibromatose por parte dos profissionais de saúde, citadas pelos entrevistados, já foram apontadas por outros pesquisadores ${ }^{1,12}$. Estes destacam o momento do diagnóstico como uma situação na qual o medo do desconhecido seria a principal reação dos pacientes e familiares. Gianordoli-Nascimento ${ }^{26}$ aponta os sentimentos de medo e ansiedade relacionados ao processo de

adoecimento ou ao fato de estar diante do inesperado em outras doenças crônicas. A autora associa o pouco conhecimento sobre as doenças por parte da sociedade em geral a reações discriminatórias diante daqueles que a tem e a informação sobre a doença ao favorecimento da elaboração de estratégias de adaptação emocional, do autocontrole e da adesão ao tratamento ${ }^{26}$.

As respostas da categoria Enfrentamento da doença revelaram a magnitude e a caracterização de como os grupos agem diante das experiências com a NF1. Percebe-se que, para os entrevistados que têm a doença, os sentidos encontrados para compreendê-la e enfrentá-la não são construídos de forma idêntica ao dos familiares de pessoas com NF1. Em outras palavras, mesmo nos casos em que o familiar convive muito proximamente com o paciente, há discrepâncias no modo como a doença é percebida por ambos. No caso dos familiares, as respostas contidas nesta categoria enfatizaram a procura por tratamentos e cuidados mais amplos de saúde, que podem ser compreendidos como busca por consultas especializadas e multidisciplinares. Percebe-se ainda, pelas respostas de Preocupação e Gravidade da doença, que para os familiares há uma ênfase nos impactos negativos relacionados à perspectiva para o futuro, ou seja, à evolução da doença. Quintas ${ }^{27}$ em trabalho realizado com pessoas com NF1 e os familiares cuidadores, identificou que há um descompasso entre os tipos e frequências de preocupações acerca da vivência com NF1 quando se analisa um ou outro grupo. Os resultados dessa autora mostraram que entre as grandes preocupações dos familiares estão aspectos relacionados com o comportamento daquele que tem a NF1, as relações sociais e amizades, assim como aspectos relacionados com a aprendizagem e a vida profissional ou escolar. Nesse mesmo trabalho, para o grupo de pacientes, tais aspectos não foram considerados como alvo de preocupações ${ }^{27}$.

No atual estudo, para o Grupo P, o enfrentamento da doença no que tange a autopercepção positiva é enfatizado e supera as vivências negativas quando se referem à vivência individual, pela capacidade de superação das dificuldades vividas. Isso pode ser identificado a partir dos sentidos contidos nas respostas da subcategoria Normal/Natural e em boa parte das respostas identificadas em Focado nas Emoções/Processos Psicológicos. Nesse sentido, deve-se considerar que as vivências de pessoas com NF1 ou de familiares nem sempre estão diretamente relacionadas aos aspectos objetivos da doença. 
No contato com o mundo social e suas exigências de sociabilidade, são enfatizadas experiências de estigmatização e preconceito, sobretudo aos aspectos nos quais a doença acomete a aparência física, a estética socialmente valorizada e ao estranhamento causado pelos neurofibromas, que podem gerar alguma deformação física. Nas respostas das pessoas com NF1, verificam-se referências a uma ação voltada para os sintomas físicos, principalmente para formas de retirada dos neurofibromas. Esses, em muitos casos, causam grande impacto na aparência física e, para os pacientes, é interpretado como uma situação que ultrapassa os aspectos estéticos e envolve questões de identidade, pois os afastam dos padrões de "normalidade" ${ }^{28}$. Korf e Rubenstein ${ }^{1}$ e Rozario ${ }^{13}$ ressaltam as consequências emocionais e os impactos sociais das alterações da aparência física em sociedades que valorizam um padrão de beleza com normas irreais, como a americana. A valorização do corpo nos dias atuais, de acordo com o estudo de Sudo e $\mathrm{Luz}^{29}$ sobre as representações sociais do "ser gordo" em revistas nacionais, pode ser identificada pela exposição frequente do corpo esbelto nu ou vestido nessas revistas. Os autores compreendem o papel da mídia como um sistema cultural complexo pretensamente neutro, que simultaneamente reflete, constrói e reconstrói representações tanto do corpo valorizado em sua perfeição estética, como da responsabilização do sujeito perante seu corpo, ao veicular informações que associam concepções médico-científicas a esses padrões estéti$\cos$, no intuito de associar a informação científica equiparada ao estatuto de verdade, à ideia de saúde, e impulsionando os leitores à necessidade de busca por ter saúde, aqui compreendida a partir desse referencial de corpo perfeito.

Para os dois grupos notaram-se falta ou baixa referência a respostas relacionadas a suporte social em detrimento de outras categorias, mesmo entre os participantes que estão vinculados à associação de apoio à NF. Esses dados, somados ao grande número de respostas observadas em Desconhecimento/ausência de explicação sobre a doença, podem sugerir que o enfrentamento da doença é feito predominantemente de forma individual, pela experiência pessoal, e não compartilhados socialmente.

Mendonça ${ }^{30}$ destaca que, nos estudos epidemiológicos envolvendo a temática da menopausa, o acesso às informações foi um dos fatores associado às vivências do climatério de forma mais tranquila. $\mathrm{O}$ autor considera relevante, no entanto, que a prestação dessas informações ultrapasse aspectos fisiológicos e biológicos, ou de apenas uma conversa franca, e possa incluir outros fatores implicados na problemática, como a representação do envelhecimento associado à inatividade ou outras temáticas que causem dúvidas e insegurança. Ao abrir um espaço para a intersubjetividade entre profissionais e usuários do serviço, ocorre, segundo o autor, a disponibilização da escuta e das trocas de conhecimento, facilitando a compreensão do processo pelo próprio sujeito, assim como a elaboração das informações a partir de sua realidade. Para o autor, dar importância a essas trocas faz-se necessário no intuito de permitir que as demandas sejam discriminadas, e as possíveis medidas de prevenção da doença ou promoção da saúde deixem de ser negligenciadas, ou que se reduzam as generalizações comuns de se atribuir todas as queixas à menopausa ou à idade, o que resultaria na estigmatização dessa mulher como poliqueixosa/ mulher velha ${ }^{30}$. Ablon ${ }^{15}$ avalia que é importante a facilitação do acesso das pessoas à obtenção de informações sobre a doença e que, quando se trata da transmissão dessa informação no contexto da NF1, acompanhar o processo de assimilação e incorporação dessas informações pelos pacientes ou familiares é necessário, uma vez que a complexidade das informações em NF1 é um fator complicador do que já é habitualmente um momento delicado: o diagnóstico de uma doença crônica e progressiva.

$\mathrm{O}$ pequeno volume de estudos dirigidos à doença, quando se compara à fibrose cística, por exemplo, que tem prevalência equivalente à da NF1, também é fator dificultador no acesso às informações ${ }^{8}$. No contexto nacional, o desconhecimento sobre a NF1 é especialmente distinto do norte-americano, não apenas quanto ao número de publicações, mas também à própria história da veiculação de informações sobre a doença pela mídia. A comoção social diante da exposição da triste história do "Homem Elefante", em meados da década de 70 nos Estados Unidos, tornou visível para a sociedade norte-americana essa doença, a qual posteriormente foi provada não se tratar da NF1, mas da Síndrome de Proteus $^{8,9,10,31}$. Ainda que essa associação traga outras dificuldades no que tange aos processos de identificação por parte das pessoas com NF1 e seus familiares, essa imagem constituiu um ponto de ancoragem que serviu a alguns fins, tais como a inserção da doença entre uma questão de saúde que merece atenção. Foi também através disso que as Instituições norte-americanas passaram receber significativa contribuição, não apenas financeira, mas na construção de centros, 
associações e fundações para o atendimento a essas pessoas e o desenvolvimento de pesquisas sobre a NF1. Não se trata aqui de incentivar essa forma particular, ou qualquer outra forma descuidada de divulgação de informações sobre a doença, mas sim de problematizar a questão da dificuldade do acesso a informações sobre a NF1.

Ramos et al. ao abordarem a temática da prevenção e tratamento do câncer salientam que a compreensão da autoestima, do cuidado de si e da promoção da vida, quando ficam restritos a uma dimensão meramente individualizante, a um problema individual, tornam-se vulneráveis a defesas psíquicas que podem servir como obstáculos. Assim como, associar a doença a aspectos que causem apenas impacto ao invés de promover mobilização, por exemplo, associando o câncer à ideia de morte, além de não favorecerem ações efetivas de prevenções ou cuidados, pois podem fortalecer sentimentos de impotência e comportamentos de passividade a partir do entendimento que enfrentar o câncer seria uma "batalha perdida por antecipação" 32 .

A ação das associações no intuito de divulgação da doença é ponto chave para o reconhecimento do portador e da restituição de seu lugar de sujeito, através da minimização dos efeitos da invisibilidade social da NF1, e para o fortalecimento da rede de suporte a essas pessoas e seus familiares.

Diante do cenário de invisibilidade social da doença, somadas a características típicas do curso clínico imprevisível da NF1, as pessoas acometidas e seus familiares estão propensos a vivências de estigmatização social e preconceitos, assim como a vivências de diversos tipos de sentimentos negativos, dado que é coerente e possivelmente justifica a frequência elevada de respostas, especialmente do Grupo $\mathrm{P}$, no que se refere às vivências de Constrangimentos Sociais. Assim, a dificuldade em encontrar espaços sociais em que possam ser reconhecidos, restringe as possibilidades de suporte social mais abrangente para essa população, que se vê diante da necessidade do desenvolvimento de estratégias de enfrentamento baseadas quase exclusivamente em recursos pessoais e individualizados.

\section{Considerações Finais}

A melhor compreensão das práticas e das representações relacionadas à saúde permite uma maior proximidade com as vivências cotidianas dos indivíduos a partir da perspectiva dos mesmos. Compreender esse ponto de vista permite vislumbrar intervenções mais eficientes no atendimento dessa população, possibilidade que não se restringe ao campo da Psicologia, mas abrange as demais especialidades. Nesse sentido, devese ressaltar ainda a utilidade de um trabalho interdisciplinar que propicie a comunicação e as trocas entre os diversos saberes, ampliando o entendimento sobre as diversas facetas da doença e seus impactos.

A escassa divulgação de informações sobre a NF é um dos pontos mais relevantes para as pessoas com NF1 e seus familiares. A desinformação dificulta as formas de apoio e alternativas mais eficazes de enfrentamento da mesma, bem como a adesão ao tratamento. Diante disso, é de fundamental importância o investimento em pesquisas e preparo dos profissionais da área de saúde, para que os impactos negativos causados na qualidade de vida dos usuários sejam, em parte, minimizados. Da mesma forma, há necessidade do fortalecimento das redes de apoio social e suporte das diversas demandas que os usuários apresentam, uma vez que a NF1 acarreta impactos de ordem psicológica, social e econômica não só para as pessoas com a doença, mas também para quem convive com elas.

Os resultados encontrados neste estudo refletem algumas representações sociais obtidas a partir de entrevistas com adultos e idosos usuários do CRNF-MG, sejam pessoas com NF1, sejam familiares. Nesse sentido, os dados obtidos podem ser diferentes daqueles identificados em outras populações. Além disso, as coletas não tiveram por objetivo o esgotamento do tema, de forma que novas coletas podem ser capazes de identificar novos conteúdos.

\section{Colaboradores}

AC Cerello trabalhou na coleta e análise dos dados, na redação e revisão do artigo; IF Gianordoli-Nascimento trabalhou na concepção, delineamento, análise dos dados e redação final; $\mathrm{AH}$ Moreira participou da construção e revisão do texto; VS Rocha trabalhou na organização e análise dos dados, confecção de planilhas e gráficos; LM Ribeiro participou da análise dos dados, da redação e revisão do texto; NA Rezende colaborou com a redação e revisão final do artigo. 


\section{Referências}

1. Korf BR, Rubestein AE. Neurofibromatosis: a handbook for patients, families, and healthcare professionals. 2a Edição. New York: Thieme Medical Publisher; 2005.

2. Friedman JM. Epidemiology of neurofibromatosis type 1. Am J Med Genet 1999; 89(1):1-6.

3. Ferner RE, Huson SN, Thomas N, Moss C, Willshaw $\mathrm{H}$, Evans DG. Guidline for the diagnosis and management of individuals with neurofibromatosis 1 . J Med Genet 2007; 44(2):81-88.

4. Ferreira SRG, Franco LJ, Vivolo MA, Negrato CA, Simões ACP, Venturelli CR. Population based incidence of IDDM in the state of São Paulo, Brazil Diabetes Care 1993; 16(5):701-704.

5. Martin GA, Viskochil D, Bollag G, McCabe PC, Croiser WJ, Haubruck H. The GAP-related domain of the neurofibromatosis type 1 gene product interacts with ras p. 21. Cell 1990; 63(4):843-849.

6. Xu G, O'Connell P, Viskochil D, Cawthon R, Robertson M, Culver M. The neurofibromatosis type 1 gene encodes a protein related to GAP. Cell 1990; 62(3):599-608.

7. Gutman DH, Wood DL, Collins FS. Identification of the neurofibromatosis type 1 gene product. Proct Natl Acad Sci USA 1991; 88(21):9658-9662.

8. Geller M, Bonalumi A. Neurofibromatose: clínica, genética e terapêutica. Rio de Janeiro: Guanabara Koogan; 2004.

9. Messner RL, Messner MR, Lewis J. Neurofibromatosis: a familial and family disorder. J Neosurg Nurs 1985; 17(4):221-229.

10. Messner RL, Gardner S, Messner MR. Neurofibromatosis - an international enigma: A framework for nursing. Cancer Nurs 1985; 8(6):314-322.

11. Benjamin CM, Colley A, Donnai D, Kingston H, Harris R, Kerzinstorrar L. Neurofibromatosis type 1 (NF1): knowledge, experience, and reproductive decisions of affected patients and families. Med Genet 1993; 30(7):567-574.

12. Ablon J. Living with Genetic Disorder: The impact of Neurofibromatosis 1. Westsport, CT: Auburn House; 1999.

13. Rozario S. Growing up and living with Neurofibromatosis 1 (NF1): A British Bangladeshi case-study. J Genet Couns 2007; 16(5):551-559.

14. Barton BE, North K. Social skills of children with neurofibromatosis type 1. Dev Med Child Neurol 2004; 46(8):553-563.

15. Ablon J. Parents' Responses to their Childs Diadnosis of Neurofibromatosis 1. Am J Med Genet 2000; 93(4):136-142.

16. Jovchelovitch S. Representações sociais e esfera púbica. Petrópolis: Vozes; 2000.

17. Jodelet D. Representações sociais: um domínio em expansão. In: Jodelet D, organizadora. Ulup L, tradução. As Representações Sociais. Rio de Janeiro: UERJ; 2001. p. 22.

18. Trindade ZA. Representação Social: "Modo de conhecer” no cenário da Saúde. In: Trindade Z, Camino C, organizadores. Coletâneas da ANPEPP: V. 1, N. 6. Cognição e Juízo Moral. Rio de Janeiro: ANPEPP; 1996. p. 45-59.
19. Sá CP. A Construção do Objeto de Pesquisa em Repre sentações Sociais. Rio de Janeiro: UERJ; 1998.

20. Abric JC. Metodologia de recolección de las representaciones sociales. In: Abric JC, organizador. Práticas sociales y representaciones. México: Ediciones Coyacán; 2001. p. 53-74.

21. Bardin L. Análise de Conteúdo. Lisboa: Editora 70; 1977.

22. Rohden F. Ginecologia, gênero e sexualidade na ciência do século XIX. Horizontes Antropológicos 2002; 8(17):101-125.

23. Braz M. A construção da subjetividade masculina e seu impacto sobre a saúde do homem: Reflexão bioética sobre justiça distributiva. Cien Saude Colet 2005; 10(1):97-104.

24. Nascimento ARA, Trindade ZA, Gianordoli-Nascimento IF, Pereira FB, Silva SATC, Cerello AC. Masculinidades e práticas de saúde na Região Metropolitana de Belo Horizonte/MG. Saúde e Sociedade 2011; 20(1):182-194.

25. Trindade ZA. Representaçoes Sociais da Paternidade da Maternidade: Implicações no Processo de Aconselhamento Genético [tese]. São Paulo: Universidade de São Paulo; 1991

26. Gianordoli-Nascimento IF. O Que Fazer Quando o Coração Aperta? A Relação Conjugal e Suas Transformações Pós-infarto [dissertação]. Vitória, ES: Universidade Federal do Espírito Santo; 2000.

27. Quintas ALS. Neurofibromatose tipo 1: principais preocupações de doentes e cuidadores de doentes [dissertação]. Lisboa: Universidade de Lisboa; 2008.

28. Goffman E. Estigma: Notas sobre a Manipulação da Identidade Deteriorada. 4a Edição. Rio de Janeiro: LTC; 2008

29. Sudo N, Luz MT. O gordo em pauta: representações do ser gordo em revistas semanais. Cien Saude Colet 2007; 12(4):1033-1040.

30. Mendonça EAP. Representações médicas e de gênero na promoção da saúde no climatério/menopausa. Cien Saude Colet 2004; 9(1):155-166.

31. Ablon J. 'The elephant man' as 'self' and 'other': the psycho-social costs of a misdiagnosis. Soc Sci Med 1995; 40(11):1481-1489.

32. Ramos C, Carvalho JEC, Mangiacavalli MASC. Impacto e (i)mobilização: um estudo sobre campanhas de prevenção ao câncer. Cien Saude Colet 2007; 12(5):1387-1396.

Artigo apresentado em 30/11/2012

Aprovado em 01/02/2013

Versão final apresentada em 07/03/2013 